\title{
Engagement Strategies to Improve Adherence and Retention in Web-Based Mindfulness Programs: Systematic Review
}

Natalie Winter ${ }^{1}, \mathrm{PhD}$; Lahiru Russell ${ }^{1,2,3}, \mathrm{PhD}$; Anna Ugalde ${ }^{1}$, PhD; Victoria White ${ }^{4}, \mathrm{PhD}$; Patricia Livingston ${ }^{1,5}, \mathrm{PhD}$

${ }^{1}$ Centre for Quality and Patient Safety Research in the Institute for Health Transformation, Deakin University, Geelong, Australia

${ }^{2}$ School of Nursing and Midwifery, Deakin University, Geelong, Australia

${ }^{3}$ Centre for Quality and Patient Safety Research - Eastern Health Partnership, Deakin University, Melbourne, Australia

${ }^{4}$ School of Psychology, Faculty of Health, Deakin University, Geelong, Australia

${ }^{5}$ Faculty of Health, Deakin University, Geelong, Australia

\section{Corresponding Author:}

Natalie Winter, $\mathrm{PhD}$

Centre for Quality and Patient Safety Research in the Institute for Health Transformation

Deakin University

1 Gheringhap Street

Geelong, 3220

Australia

Phone: 61352271100

Email: n.heynsbergh@deakin.edu.au

\section{Abstract}

Background: Web-based mindfulness programs may be beneficial in improving the well-being outcomes of those living with chronic illnesses. Adherence to programs is a key indicator in improving outcomes; however, with the digitization of programs, it is necessary to enhance engagement and encourage people to return to digital health platforms. More information is needed on how engagement strategies have been used in web-based mindfulness programs to encourage adherence.

Objective: The aim of this study is to develop a list of engagement strategies for web-based mindfulness programs and evaluate the impact of engagement strategies on adherence.

Methods: A narrative systematic review was conducted across the MEDLINE Complete, CINAHL Complete, APA PsycINFO, and Embase databases and followed the PRISMA (Preferred Reporting Items for Systematic Reviews and Meta-Analysis) guidelines. Articles were screened using the population, intervention, comparator, and outcome framework. Adults aged $>18$ years with chronic health conditions were included in the study. Mindfulness interventions, including those in combination with mindfulness-based cognitive therapy, delivered on the web through the internet or smartphone technology were included. Interventions lasted at least 2 weeks. Studies with a randomized controlled trial design or a pilot randomized controlled trial design were included. Engagement strategies, including web-based program features and facilitator-led strategies, adherence, and retention, were included.

Results: A total of 1265 articles were screened, of which 19 were relevant and were included in the review. On average, $70.98 \%$ (2258/3181) of the study participants were women with a mean age of 46 (SD 13) years. Most commonly, mindfulness programs were delivered to people living with mental health conditions $(8 / 19,42 \%)$. Of the 19 studies, $8(42 \%)$ used only program features to encourage adherence, $5(26 \%)$ used facilitator-led strategies, and $6(32 \%)$ used a combination of the two. Encouraging program adherence was the most common engagement strategy used, which was used in $77 \%(10 / 13)$ of the facilitator-led studies and $57 \%(8 / 14)$ of the program feature studies. Nearly two-thirds $(63 \%)$ of the studies provided a definition of adherence, which varied between $50 \%$ and $100 \%$ completion across studies. The overall mean participant compliance to the mindfulness programs was $56 \%$ (SD 15\%). Most studies (10/19, 53\%) had a long-term follow-up, with the most common follow-up period being 12 weeks after intervention $(3 / 10,30 \%)$. After the intervention, the mean retention was $78 \%$ (SD $15 \%$ ).

Conclusions: Engagement strategies in web-based mindfulness programs comprise reminders to use the program. Other features may be suitable for encouraging adherence to interventions, and a facilitator-led component may result in higher retention. There is variance in the way adherence is measured, and intervention lengths and follow-up periods are inconsistent. More thorough reporting and a standardized framework for measuring adherence are needed to more accurately assess adherence and engagement strategies. 
(J Med Internet Res 2022;24(1):e30026) doi: 10.2196/30026

\section{KEYWORDS}

chronic disease; chronic illness; digital health; digital technology; internet mindfulness; mindfulness based stress reduction; patient dropouts; mobile phone

\section{Introduction}

\section{Background}

Mindfulness is the act of bringing awareness to the present moment in a nonjudgmental and accepting way [1]. Mindfulness programs are increasing in popularity as nonpharmacological alternatives to manage both physiological and psychological outcomes related to health conditions [2]. Psychological benefits are evident in individuals across a variety of conditions, including cancer [3] and mental illness [4], and physical health outcomes have been observed through improved blood pressure control [5] and improved glycemic control in people living with diabetes [6].

Evidence shows that mindfulness skills can be improved through greater engagement with meditation, home practice, face-to-face contact with a facilitator, and a higher number of sessions per week [7]. High adherence to both face-to-face and web-based mindfulness programs results in significant improvements in well-being outcome measures [8,9].

Mindfulness programs are increasingly being adapted to web-based platforms, providing opportunities for more people to participate compared with conventional face-to-face sessions [10]. Typically, adherence to web-based interventions is low, both with program adherence and study attrition [11]. Program adherence is poorly defined but needs to be standardized across studies; however, it is commonly conceptualized by the number of log-ins or number of sessions or modules completed in a program [12].

Adherence to web-based programs in previous reports has varied between $39.5 \%$ and $92 \%$ [9] compared with adherence to face-to-face settings, where the rates ranged between $26 \%$ and $100 \%$ [13] (based on definitions of 100\% program completion). Mindfulness programs are often 8 weeks long in duration [9], with higher adherence having an impact on improved participant outcomes [14]. There is a need to explore whether engagement strategies can improve adherence to unmoderated web-based interventions. High attrition in telehealth interventions is common and can undermine the potential impact of programs [15]. Adherence to mindfulness-based interventions is often poorly defined and inconsistent across studies [16]. Promoting long-term adherence and engagement with web-based interventions may maximize the potential outcomes [17].

Engagement refers to the frequency and duration of use of the interventions, such as logging in and out of programs [18]. Strategies to support engagement are used to encourage and draw people back to the interventions [18]. Engagement can be enhanced by the design and features of web-based interventions, including the use of gamification, breaking content into manageable blocks, and using a variety of formats to deliver content such as video and visuals [19]. Other considerations for improving engagement include guided interaction from trained personnel [18], asynchronous emails [20], or web-based features such as reminders [18]. Behavior change techniques are engagement strategies incorporated into interventions to promote sustainable changes in behavior [21]. Behavior change techniques, such as notifications and semiautomated tracking, have previously been adopted in app-based interventions and have shown a positive impact on improving engagement [22]. In mindfulness programs, engagement involves regular meditation and daily awareness exercises coupled with intention motivation and commitment to practice [23]. Techniques such as self-reflection are incorporated into mindfulness programs and have been shown to positively impact symptoms in people with anxiety and stress [24]. More recent techniques such as machine learning [25] may also be used to tailor interventions to user-specific needs, thereby maximizing the clinical outcomes of users.

The influence of engagement strategies on program adherence has not been compared across studies; however, it is an important consideration when designing and implementing web-based interventions. In this review, we explored the engagement strategies applied in web-based mindfulness programs and evaluated whether these strategies had an impact on program adherence and retention.

\section{Research Question}

The following research question was used in the study: how can engagement strategies be incorporated into web-based mindfulness programs to improve adherence and retention?

\section{Objectives}

The objectives of this study are (1) to develop a list of engagement strategies for web-based mindfulness programs and (2) to evaluate the impact of engagement strategies on adherence.

\section{Methods}

\section{Search Process}

This systematic review was guided by the PRISMA (Preferred Reporting Items for Systematic Reviews and Meta-Analysis) framework [26]. The following databases were searched for terms related to mindfulness, web-based programs, and engagement strategies: MEDLINE Complete, CINAHL Complete, APA PsycINFO, and Embase. The literature search focused on identifying papers published between January 2015 and March 2020. A 5-year period was chosen to capture the most recent web-based interventions. See Table S1 in Multimedia Appendix 1 for an example of the search strategy applied to the MEDLINE database. The reference lists of relevant articles and systematic reviews were searched for additional articles. 


\section{Eligibility Criteria}

To guide the eligibility and screening process, the PICO (population, intervention, comparator, and outcome) framework [27] was used:

\section{Population}

Adults aged $\geq 18$ years with a diagnosed chronic health condition or self-reported anxiety or depression were included in the study.

\section{Intervention}

Mindfulness interventions delivered on the web through the internet or smartphone technology were included. Mindfulness programs were defined as those focusing specifically on mindfulness-based practice, including programs using a combination of mindfulness and cognitive behavioral therapy (mindfulness-based cognitive therapy).

To allow for engagement strategies and adherence to be analyzed, the interventions had to be at least 2 weeks in duration. There is limited research to describe how long interventions should be to warrant the inclusion of engagement strategies. Previously, engagement was measured by reflecting on the previous 2 weeks [23]. Therefore, we determined that interventions had to be at least two weeks in duration to be included in the review.

\section{Comparator and Context}

Studies were required to have a comparison group with a randomized controlled trial (RCT) or a pilot RCT design.

Mindfulness programs developed by research groups for specific populations or commercially available mindfulness programs were tested in controlled trial settings.

\section{Outcomes}

Program adherence, study retention rate (\%), and strategies such as web-based program features and facilitator-led features were included.

\section{Screening}

Retrieved articles were uploaded and managed by Endnote X9 (Clarivate Analytics). Duplicates were removed, and titles and abstracts were screened by 1 author $(\mathrm{NH})$. Full-text articles were uploaded to Covidence to allow cross-checking between authors [28]. Full texts were reviewed independently by 2 authors, and any disagreements were resolved through discussion.

\section{Data Extraction}

A data extraction tool was developed in Microsoft Excel to standardize the extraction. Data were extracted by 1 author (NH), and $10 \%$ were cross-checked by the second author (PL).

\section{Study Characteristics}

Study data including author, year of publication, country, design, number of participants, intervention type, intervention duration, follow-up measurements, prior mindfulness experience, recruitment method, financial compensation, commercial app name, primary outcome, and primary findings were extracted.

\section{Participant Characteristics}

Gender, age, race, ethnicity, type of chronic illness or condition, and patient and caregiver status were extracted.

\section{Adherence}

Studies were included in the review when they reported per-protocol and intention-to-treat analyses. Because of variance in reporting the intervention, adherence was assessed in 3 different ways depending on the data available:

1. As a percentage of compliance with the intervention protocol. For example, some authors defined adherence as $80 \%$ program completion, and in this review, we recorded the percentage of the sample that was adherent with $80 \%$ program completion.

2. In groups defined by the study authors. For example, in an 8-week program, some authors reported the percentage of people who were adherent with 0- 3 sessions, 4 - 6 sessions, and 7-8 sessions. In this review, we recorded the percentage of the sample that was adherent with the highest group of completion, for example, 7-8 sessions.

3. Summarized findings of the frequency and duration of use.

\section{Retention}

Retention rates were reported for the intervention group at postintervention measurements and subsequent follow-up points.

\section{Engagement Strategies}

Engagement strategies were categorized into following 3 groups:

1. Program features, including chat rooms, discussion boards, diaries and reflective processes, automated reminders, social support, goal setting, mood tracking, customization of content, demonstrations of meditation practice, and immediate feedback on meditation practice;

2. Facilitator-led strategies, including reminders from the research team to continue practice, contact with the research team to discuss practice or monitoring, and response to well-being scores throughout the intervention; and

3. A combination of program features and facilitator-led strategies.

\section{Data Analysis}

Study characteristics, participant characteristics, adherence, and retention rates were analyzed using descriptive statistics.

Data analysis consists of the following:

1. Exploring adherence: how adherence was defined, the impact of adherence on outcomes, impact of financial compensation on adherence, and impact of intervention length on adherence.

2. Describing retention at postintervention measurements and the last data collection point.

3. Describing engagement strategies (program features, facilitator-led strategies, or a combination): engagement strategies were categorized and summarized using frequency statistics

4. Assessing the impact of engagement strategies on adherence: the relationship between engagement strategies and adherence was analyzed by comparing the type of 
engagement strategy (program features, facilitator-led strategies, or a combination) with the percentage of people who reached program adherence or the percentage of people who adhered with the highest group of sessions (eg, those who completed 7-8 sessions in an 8-week program, as defined by the study authors).

- Assessing the impact of engagement strategies on retention: the relationship between engagement strategies and retention was measured by comparing the type of engagement strategy with the intervention length, retention at the postintervention measurement and retention at the last follow-up points.

\section{Results}

\section{Study Characteristics}

A total of 1922 articles were retrieved from the databases and reference lists. After removing duplicates, a total of 1265 articles were screened by title and abstract. Full texts were retrieved for 126 articles, of which 19 were included in the review (Figure
1). Most studies were conducted in the United States $(9 / 19$, $47 \%) \quad[5,24,29-35]$, were RCTs (16/19, 84\%) [5,14,24,29,31-33,35-43], web-based (11/19, 58\%) [3,14,33-35,37-43], and focused specifically on mindfulness or meditation $(15 / 19,79 \%)$ [3,5,14,29-32,34-36,39-43] (Table S2 in Multimedia Appendix 1) [3,5,14,24,27,29-41,43]. More studies $(10 / 19,52 \%)$ excluded people with previous or recent mindfulness experiences [24,29-31,37,39,42,43] than those who allowed participants with prior mindfulness experience $(6 / 19$, $31 \%$ ) $[3,14,32,34,35,38,40,41]$. Over half of the studies used a combination of web-based and face-to-face recruitment strategies $\quad(10 / 19, \quad 52 \%) \quad[5,29,31,32,34,35,37,39,40,42]$. Commercially available mindfulness apps, including Headspace $(n=3)[30,32,36]$, Calm $(n=1)$ [29], and Pacifica $(n=1)$, were used by $5(26 \%)$ studies [24]. A total of $3(16 \%)$ studies provided monetary compensation for participation [29,30,33], and $3(16 \%)$ provided access to paid mindfulness apps $[30,32,36]$. Intervention duration ranged from 2 weeks to 12 months, with over half $(10 / 19,53 \%)$ of the studies having an intervention duration of 8 weeks [29,30,32,33,36,37,39,40,42,43].

Figure 1. PRISMA (Preferred Reporting Items for Systematic Reviews and Meta-Analysis) diagram of the search process.
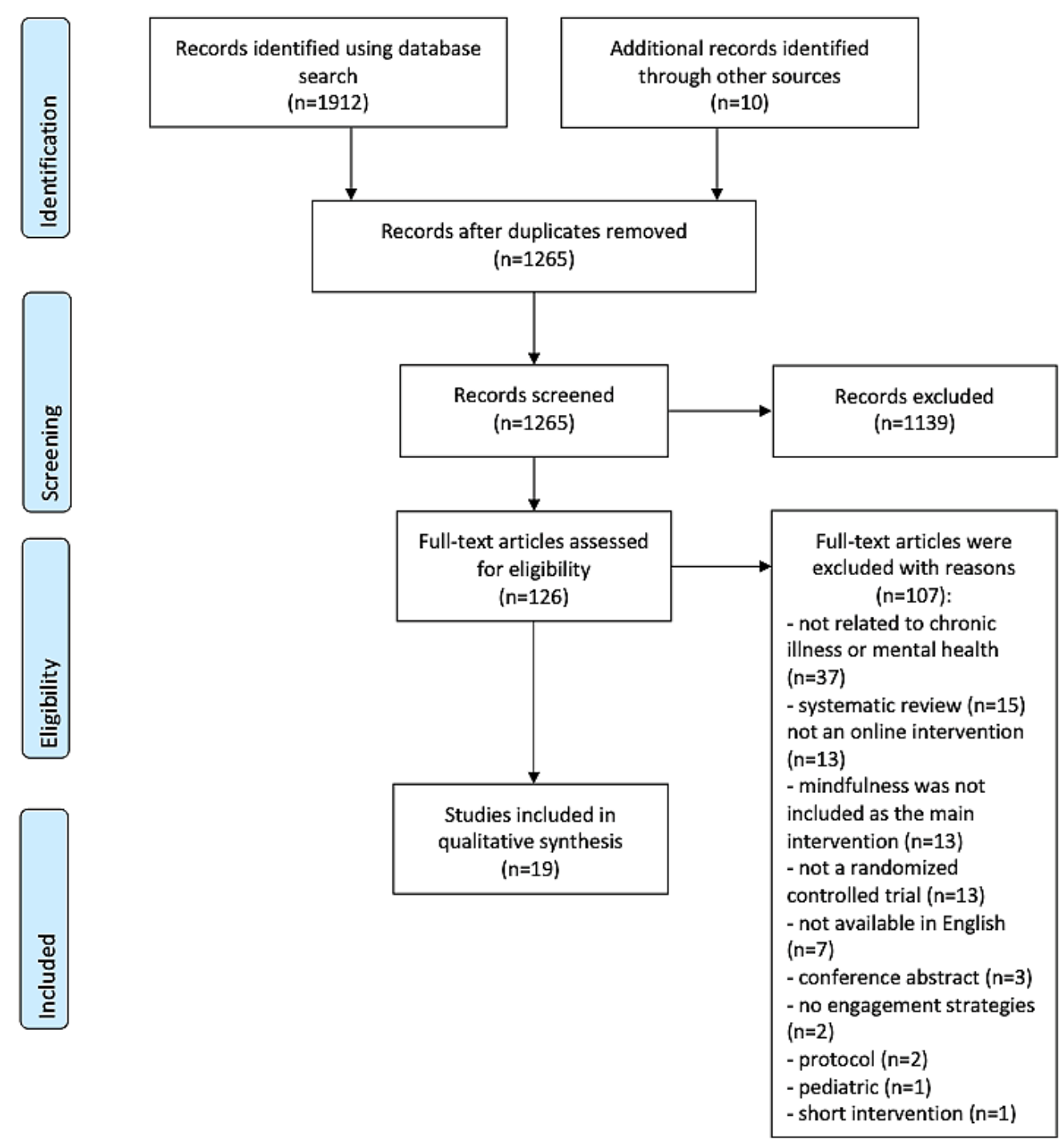
A total of $8(47 \%)$ studies focused on psychological measures as their primary outcome [29,31-34,37-39,42], and $3(16 \%)$ used a physiological measure [5,14,41]. A total of $7(37 \%)$ studies did not report the primary outcome $[3,24,30,35,36,40,43]$. Secondary outcomes were predominately psychological measures and program evaluations $(8 / 19,42 \%)$ [16,24,30,32,34,38,39,42]. Most $(17 / 19,90 \%)$ studies showed that mindfulness resulted in a significant improvement in outcomes either psychological or physical [3,5,14,24,29-34,36,37,39-43] (Table S3 in Multimedia Appendix 1) $[3,5,14,27,29-41,43]$.

\section{Participant Characteristics}

A total of 34,601 participants were included in the trials. The mean sample size was 165 (SD 134; range 21-500). On average, $71 \%$ of the participants were women (SD 18; range 46-100) and 46 years old (SD 13; range 21-76). A total of 8 (42\%) studies reported the ethnicity of the participants [24,29-35,39], and $4(26 \%)$ reported race [29,31-33]. On average, White people comprised $74 \%$ (SD 14\%) of the sample and 90\% (SD 10\%) were non-Hispanic. Mindfulness programs were delivered to people with a variety of chronic illnesses, with the most common conditions related to mental health $(8 / 19,42 \%)$ [24,29,31,33-36,38] and cancer $(4 / 19,21 \%)[3,30,32,37]$. Most $(17 / 21,81 \%)$ studies were delivered to people living with the illness [3,5,14,24,29,31-41,43].

\section{Engagement Strategies}

A total of $8(42 \%)$ studies used only program features to encourage adherence, 5 (26\%) used only facilitator-led strategies, and $6(32 \%)$ used a combination of the two (Table $1)$.

Within the facilitator-led strategies $(\mathrm{n}=13)$ [5,30,31,33-38,42,43], encouraging adherence was most commonly done using contact and reminders from facilitators to use the program $(10 / 13,77 \%)[30,31,33-36,38,42]$. Contact with a facilitator for discussion of content or well-being scores was used to a lesser extent $(4 / 13,31 \%)[5,37,38,43]$. In $7(37 \%)$ studies, engagement with facilitators occurred weekly [34-37,42,43].

Table 1. Types of engagement strategies used across studies and their adherence rates.

\begin{tabular}{|c|c|c|c|}
\hline Study & Program engagement & Facilitator engagement & Adherence with study protocol (\%) \\
\hline Chandler et al [5] & $\checkmark$ & $\checkmark$ & 39 \\
\hline Compen et al [37] & $\checkmark$ & $\checkmark$ & 79 \\
\hline Kladnitski et al [38] & $\checkmark$ & $\checkmark$ & 66 \\
\hline Kubo et al [30] & $\checkmark$ & $\checkmark$ & 56 \\
\hline Stjernsward and Hansson [27] & $\checkmark$ & $\checkmark$ & 57 \\
\hline Thompson et al [33] & $\checkmark$ & $\checkmark$ & $\mathrm{NR}^{\mathrm{a}}$ \\
\hline Gotink et al [14] & $\checkmark$ & $\mathrm{N} / \mathrm{A}^{\mathrm{b}}$ & 50 \\
\hline Hearn and Finlay [39] & $\checkmark$ & N/A & 72 \\
\hline Henriksson et al [40] & $\checkmark$ & N/A & 58 \\
\hline Huberty et al [29] & $\checkmark$ & N/A & NR \\
\hline Moberg et al [24] & $\checkmark$ & N/A & NR \\
\hline Rosen et al [32] & $\checkmark$ & N/A & NR \\
\hline Russell et al [3] & $\checkmark$ & N/A & NR \\
\hline Younge et al [41] & $\checkmark$ & N/A & 53 \\
\hline Bostock et al [36] & N/A & $\checkmark$ & 27 \\
\hline Lindsay et al [31] & N/A & $\checkmark$ & NR \\
\hline Tavallaei et al [43] & N/A & $\checkmark$ & NR \\
\hline Wahbeh et al [35] & N/A & $\checkmark$ & NR \\
\hline Wahbeh [34] & N/A & $\checkmark$ & NR \\
\hline
\end{tabular}

${ }^{\mathrm{a}} \mathrm{NR}$ : not recorded.

${ }^{\mathrm{b}} \mathrm{N} / \mathrm{A}$ : not applicable.

Within program feature strategies $(\mathrm{n}=14)$ [3,5,14,24,29,30,32,33,37-42], participants in 57\% (8/14) studies received automated reminders [3,5,14,29,30,32,40,41]. Half of the program reminders were received at least once a week $[3,14,32,41]$, and the remaining were sent on an ad hoc basis $[29,30]$ or participants were able to personalize whether they received notifications or not [5,30]. Other program features used to encourage adherence included the ability to personalize mindfulness course content $(4 / 14,29 \%)[5,25,26,28]$, homework activities $(3 / 14,21 \%)[33,37,38]$, self-reflections $(2 / 14,14 \%)$ $[37,42]$, social contact $(3 / 14,21 \%)[5,24,33]$, personalization of app appearance $(2 / 14,14 \%)[5,24]$, lesson summaries $(1 / 14$, 
7\%) [38], progress tracking of mindfulness practice (1/14, $7 \%)[24]$, immediate feedback on practice $(1 / 14,7 \%)$ [5], demonstration videos $(1 / 14,7 \%)$ [39], goal setting $(1 / 14,7 \%)$ [24], tracking psychological outcomes $(1 / 14,7 \%)$ [24], and tracking physical health $(1 / 14,7 \%)$ [24] (Table S4 in Multimedia Appendix 1) [3,5,14,24,29-35,37-41,43].

Contact initiated by facilitators or program reminders was most commonly delivered by email $(9 / 14,64 \%)$ [3,14,33,36-38,40-42] or telephone $(7 / 14,50 \%)$ [30,31,33-35,38,43].

\section{Adherence}

Nearly two-thirds $(12 / 19,63 \%)$ of the studies provided a definition of program adherence [3,5,14,30,33,36-42]. When defined as the percentage of program completion, the definitions of adherence varied between 50\% and $100 \%$ program completion across studies. When adherence was grouped, the highest group of completion varied from $50 \%$ to $100 \%$ among the studies. A total of $6(32 \%)$ studies did not provide a measurement for adherence and analyzed program use descriptively [24,29,31,32,34,35]. Moreover, 1 (5\%) study did not report adherence or program use [43]. The percentage of people who complied with the authors' definitions of adherence ranged from $27 \%$ to $79 \%$, with a mean compliance of $56 \%$ (SD $15 \%)$.

\section{The Impact of Engagement Strategies on Adherence}

Among studies that used only program features $(n=8)$ [3,14,24,29,32,39-41], 4 recorded adherence between $50 \%$ and $72 \%$ (mean 58\%, SD 8\%) [14,39-41] (Table S3 in Multimedia Appendix 1). Among studies that used only facilitator-led strategies $(n=5)[31,34-36,43]$, only 1 reported adherence of $27 \%$ [36]. Among studies that used a combination of program features and facilitator-led strategies $(n=6)[5,30,33,37,38,42]$, 7 recorded adherence between $39 \%$ and $79 \%$ (mean 59\%, SD 13) $[5,30,37,38,42]$.

When examining studies that used program features, of the studies that used 1 strategy $(n=6)[3,14,39-42], 5$ measured adherence rates between $50 \%$ and $72 \%$ (mean 58\%, SD 8\%). Of the studies that used 2 strategies $(n=8)[29,30,32,33,37,38]$, 3 measured adherence between $56 \%$ and $79 \%$ (mean $67 \%$, SD $9 \%$ ). A total of 5 studies did not include any engagement strategies within their program [15,34-36,43], and $2[5,24]$ used $\geq 5$ strategies; adherence was only recorded in 2 of these studies, and they were below $40 \%$. Studies that involved only program reminders as engagement strategies $(n=4,3$ studies recorded adherence) $[3,14,40,41]$ had an average adherence rate of $54 \%$ (SD 3\%) compared with the average adherence rate of $48 \%$ (SD $8 \%$ ) of those studies that used reminders and other strategies $(\mathrm{n}=4$, only 2 recorded adherence) $[5,29,30,32]$, and the average adherence rate of $69 \%$ of those studies that did not use program reminders but only used other strategies $(n=6,4$ recorded adherence) [24,33,37-39,42].

\section{How Adherence Affected Outcomes}

A total of 10 (53\%) studies analyzed the relationship between outcome variables and adherence [14,24,30,32,34,36,38-40,42]. Of them, 4 studies found that people who had higher adherence to mindfulness programs had a significantly higher improvement in outcomes [30,36,40,42]; 1 study found that people with higher scores for depression at baseline were less likely to be adherent or complete mindfulness programs [39]; 1 found that people with higher blood pressure readings were more likely to be compliant [14]; and 1 showed that higher quality of life scores at baseline were significantly associated with improved adherence [32]. A total of 3 studies found no relationship between baseline scores and adherence or adherence and outcome variables [24,34,38].

\section{Financial Compensation and Program Adherence}

Of the 6 studies that provided any type of compensation, 2 measured adherence with a mean of $42 \%$ (SD 15\%; range 27-56) $[30,36]$. Among the studies that did not offer financial compensation, the majority $(8 / 13,62 \%)$ measured adherence with a mean of $60 \%$ (SD 11\%; range 39-79) [5,14,37-42].

\section{Intervention Length and Program Adherence}

The impact of the intervention length on adherence was analyzed. Of the 5 studies with an intervention $<8$ weeks, none recorded adherence. Those with an 8 -week intervention recorded an average of $58 \%$ (SD 16\%) adherence $(6 / 10,60 \%$ of the studies measured adherence) [30,36,37,39,40,42]; those with interventions $>8$ weeks recorded an average of 52\% (SD 9\%) adherence $(4 / 4,100 \%$ of the studies measured adherence) $[5,14,38,41]$.

\section{Retention}

Most (10/19, 53\%) studies conducted pre-post analysis with additional follow-up points [14,24,29,32-34,36,38,39,42]. Follow-up periods ranged from 4 to 36 weeks after intervention, and the most frequent follow-up time was 12 weeks after the intervention $(3 / 10,30 \%)[38,39,42]$. After intervention, most $(14 / 19,74 \%)$ studies had over $70 \%$ retention (mean $78 \%$, SD $15 \%$; range $35 \%-100 \%$ ) [3,5,29-31,33-39,41,43]. At the last follow-up point, 4 studies had retention above $70 \%$ [14,33,36,38].

\section{The Impact of Engagement Strategies on Retention}

Studies that applied only facilitator-led strategies, on average, were 6 weeks in duration (SD 2; range 2-8) and had a retention rate of $93 \%$ (SD 10; range 73-100) compared with studies with a combination of program features and facilitator-led strategies with a mean duration of 16 weeks (SD 10; range 8-52) and a retention rate of 75\% (SD 5\%; range 69-84) and those with only program features with a mean duration of 8 weeks (SD 2; range 4-12) and retention rate of $67 \%$ (SD 15\%; range 30-79).

Of the studies that used facilitator-led strategies only, $40 \%(2 / 5)$ had follow-up periods after postintervention follow-up [34,36]. On average, follow-up was 7 (range 6-8) weeks and retention was $76 \%$ (SD 15\%; range 69-82). Of the 6, 5 (50\%) studies using a combination of program features and facilitator-led strategies had long-term follow-up, which, on average, was 11 weeks (SD 0.9; range 10-12), with a retention rate of $71 \%$ (SD 15 ; range 49-83) $[33,38,42]$. Of the $8,5(63 \%)$ studies using program features only also had a long-term follow-up period of, on average, 13 (range 4-36) weeks, with retention rates of $53 \%$ (SD 18; range 20-74) [14,24,29,32,39]. 
Studies that used only program reminders as engagement strategies $(n=4)[3,14,40,41]$ had mean retention rates of $71 \%$ after intervention $(n=3)[3,40,41]$ and retention of $74 \%$ at the last follow-up point $(n=1)$ [14]. Studies that used reminders and other strategies $(n=4)[5,29,30,32]$ had a mean retention of $78 \%$ after intervention $(n=3)[5,29,30]$ and $57 \%$ at the last follow-up point $(n=2)[29,32]$. Studies that did not use program reminders but only used other strategies $(n=8)[24,33,37-39,42]$ had a mean retention of $67 \%$ after intervention $(n=6)[24,33,37-39,42]$ and $58 \%$ at the last follow-up point $(n=5)[24,38,39,42]$.

\section{Discussion}

\section{Principal Findings}

In this review, we described the engagement strategies applied to web-based mindfulness programs and their impact on adherence rates. The use of program features only was associated with program adherence but not with maintaining study retention. Engagement strategies were largely reminders to use the program and, to a lesser extent, the ability to customize program content, interact with features, or engage with content on a deeper level through reflections, homework activities, and discussions of content with facilitators. There was little difference between the type of engagement strategy used and adherence to programs or retention rates.

The need to accurately report study and program attrition to better understand the associations between program adherence and health outcomes has been established $[11,12]$. Our review found variability across studies in adherence measurements and inconsistencies in reporting adherence. Some studies measured adherence as completing a specific percentage of the program $[3,14,30,37,39,41]$. Other studies described adherence by grouping the number of sessions completed [5,33,36,38,40,42] or by describing use [24,29,31,32,34,35]. Although findings suggest that program adherence is similar between interventions using program features only and those using a combination of program features and facilitator-led strategies, these results should be interpreted with caution because of the variability in reporting. The variability in measuring adherence is consistent in the e-therapy literature [44] and limits the ability to assess the relationships between adherence to and engagement with web-based interventions and user outcomes. Future studies should consider reporting adherence as a percentage of program completion for easier comparisons across studies.

Similarly, the ability to measure the impact of engagement strategies on study attrition is limited. The findings suggest that studies using only facilitator-led strategies were favorable for maintaining study retention $[31,34-36,43]$. On average, at the postintervention measurement, studies with only facilitator-led strategies had a retention rate of $93 \%$ (SD 10\%) compared with the rate of those using only program features of $67 \%$ (SD 15\%). Similar findings were observed during the follow-up period (76\%, SD $7 \%$ vs 53\%, SD 18\%a). However, there is limited evidence as to whether the presence of the facilitator was the reason for this variability or whether other factors such as intervention length, follow-up length, or demographic characteristics of participants contributed to attrition. For example, 1 study that used only program features to improve engagement had low retention after intervention (35\%) and at the 8-week follow-up (20\%) [24]. No information was provided regarding the reason for these high attrition rates, making it difficult to determine the cause of these findings. The use of a facilitator or therapist to guide web-based psychological programs has been debated $[45,46]$. Studies of cognitive behavioral therapy interventions found that the presence of a therapist as a facilitator improved symptoms of depression compared with interventions with no facilitator [46]. However, improvements in anxiety symptoms were similar across studies [46], and no information was provided about whether the presence of a facilitator affected adherence. Improvements in patient outcomes may also be explained by the presence of comorbidities, including physical and mental illnesses, on which mindfulness may have a positive impact [47]. Therefore, participation in a mindfulness program targeting 1 disease may have additional benefits for other comorbid conditions. Furthermore, studies that used only facilitator-led strategies experienced, on average, a higher retention rate, which is similar to previous reviews that have described that self-directed interventions often require low levels of support from facilitators [16]. The use of facilitators to encourage adherence, or therapists to deliver content, needs to be weighed against the sustainability goals, cost of the program and length of the intervention during trials, and potential scaling after implementation.

Most studies in this review showed that web-based mindfulness resulted in improvements in either psychological or physiological outcome measures [3,5,14,24,29-34,36,37,39-43]. Two key findings from this review further highlighted the relationship between study retention and baseline functioning of participants, where those with poorer psychological well-being at baseline were more likely to drop out [39], and those with higher adherence were more likely to experience greater improvements in outcomes $[30,36,40,42]$. This is similar to previous findings where higher levels of worry and rumination at baseline resulted in disengagement from mindfulness-based interventions [23]. Stricter measurements of adherence are required in future studies to fully understand the role of adherence in the success of interventions.

Program features applied throughout studies to enhance engagement varied according to the type and number of features available to users. Furthermore, the number and type of features included had similar impacts on program adherence and study retention, suggesting that there may not be one superior feature to be included in programs. Features such as diaries, reminders, and social connectedness are commonly used in interventions as behavior change techniques [21], and web-based features have been shown to be successful in improving user outcomes in other e-interventions [48]. Within mindfulness, more specific reporting is needed to assess how often users engage with each type of feature to determine the relationship among engagement strategies, adherence, and outcomes.

\section{Limitations}

Across studies, there was a large variance in interventions and in reporting adherence. These factors made it difficult to draw any firm conclusions from the data. 
The sample of the included studies was predominately White and female, which limits the generalizability of these findings to other population groups.

This review aims to describe the influence of engagement strategies on adherence and retention among people living with chronic illnesses or conditions. Other studies measuring adherence to mindfulness in the general population may have provided additional information on the impact of engagement strategies. However, there is a need to evaluate engagement and adherence to web-based interventions, specifically in people living with chronic illness. People with chronic illness may be more likely to experience depression and anxiety symptoms than those without a chronic illness [49]. Lower mental well-being can affect the use of and engagement with web-based interventions.
Furthermore, the primary outcome of the review was to assess adherence, retention, and engagement strategies rather than to draw conclusions about the effectiveness of interventions on patient outcomes. As a result, the risk of bias assessment was less relevant.

\section{Conclusions}

Engagement strategies in web-based mindfulness programs largely comprise reminders to use the program. The impact of other features such as personalization, self-reflection activities, and lesson summaries on adherence requires further investigation. There is variance in the way adherence is measured, and intervention lengths and follow-up periods are inconsistent. More thorough reporting and a standardized framework for measuring adherence are needed to more accurately assess adherence and engagement strategies.

\section{Conflicts of Interest}

None declared.

\section{Multimedia Appendix 1}

Study demographics, examples of search strategy, and adherence, retention, and engagement strategies and outcomes. [DOCX File, 53 KB-Multimedia Appendix 1]

\section{References}

1. Kabat-Zinn J. Full Catastrophe Living; Using the Wisdom of Your Body and Mind to Face Stress, Pain and Illness. London, UK: Piatkus; 1996:59-66.

2. Niazi AK, Niazi SK. Mindfulness-based stress reduction: a non-pharmacological approach for chronic illnesses. N Am J Med Sci 2011 Jan;3(1):20-23 [FREE Full text] [doi: 10.4297/najms.2011.320] [Medline: 22540058]

3. Russell L, Ugalde A, Orellana L, Milne D, Krishnasamy M, Chambers R, et al. A pilot randomised controlled trial of an online mindfulness-based program for people diagnosed with melanoma. Support Care Cancer 2019 Jul 30;27(7):2735-2746. [doi: 10.1007/s00520-018-4574-6] [Medline: 30506103]

4. Potes A, Souza G, Nikolitch K, Penheiro R, Moussa Y, Jarvis E, et al. Mindfulness in severe and persistent mental illness: a systematic review. Int J Psychiatry Clin Pract 2018 Nov 07;22(4):253-261. [doi: 10.1080/13651501.2018.1433857] [Medline: 29411670]

5. Chandler J, Sox L, Diaz V, Kellam K, Neely A, Nemeth L, et al. Impact of 12-month smartphone breathing meditation program upon systolic blood pressure among non-medicated stage 1 hypertensive adults. Int J Environ Res Public Health 2020 Mar 17;17(6):1955 [FREE Full text] [doi: 10.3390/ijerph17061955] [Medline: 32192020]

6. Rosenzweig S, Reibel DK, Greeson JM, Edman JS, Jasser SA, McMearty KD, et al. Mindfulness-based stress reduction is associated with improved glycemic control in type 2 diabetes mellitus: a pilot study. Altern Ther Health Med 2007;13(5):36-38. [Medline: 17900040 ]

7. Strohmaier S. The relationship between doses of mindfulness-based programs and depression, anxiety, stress, and mindfulness: a dose-response meta-regression of randomized controlled trials. Mindfulness 2020 Mar 02;11(6):1315-1335 [FREE Full text] [doi: 10.1007/s12671-020-01319-4]

8. Ribeiro L, Atchley RM, Oken BS. Adherence to practice of mindfulness in novice meditators: practices chosen, amount of time practiced, and long-term effects following a mindfulness-based intervention. Mindfulness (N Y) 2018 Apr;9(2):401-411 [FREE Full text] [doi: 10.1007/s12671-017-0781-3] [Medline: 30881517]

9. Spijkerman M, Pots W, Bohlmeijer E. Effectiveness of online mindfulness-based interventions in improving mental health: a review and meta-analysis of randomised controlled trials. Clin Psychol Rev 2016 Apr;45:102-114 [FREE Full text] [doi: 10.1016/j.cpr.2016.03.009] [Medline: 27111302]

10. Mrazek AJ, Mrazek MD, Cherolini CM, Cloughesy JN, Cynman DJ, Gougis LJ, et al. The future of mindfulness training is digital, and the future is now. Curr Opin Psychol 2019 Aug;28:81-86. [doi: 10.1016/j.copsyc.2018.11.012] [Medline: 30529975]

11. Eysenbach G. The law of attrition. J Med Internet Res 2005;7(1):e11 [FREE Full text] [doi: 10.2196/jmir.7.1.e11] [Medline: 15829473]

12. Sieverink F, Kelders SM, van Gemert-Pijnen JE. Clarifying the concept of adherence to eHealth technology: systematic review on when usage becomes adherence. J Med Internet Res 2017 Dec 06;19(12):e402 [FREE Full text] [doi: 10.2196/jmir.8578] [Medline: 29212630] 
13. Stanic J, Barth J, Danon N, Bondolfi G, Jermann F, Eicher M. Adherence to standardized 8-week mindfulness-based interventions among women with breast or gynecological cancer: a scoping review. J Psychosos Oncol Res Pract 2021;3(2):e048. [doi: 10.1097/OR9.0000000000000048]

14. Gotink RA, Younge JO, Wery MF, Utens EM, Michels M, Rizopoulos D, et al. Online mindfulness as a promising method to improve exercise capacity in heart disease: 12-month follow-up of a randomized controlled trial. PLoS One 2017;12(5):e0175923 [FREE Full text] [doi: 10.1371/journal.pone.0175923] [Medline: 28486559]

15. Linardon J, Fuller-Tyszkiewicz M. Attrition and adherence in smartphone-delivered interventions for mental health problems: a systematic and meta-analytic review. J Consult Clin Psychol 2020 Jan;88(1):1-13. [doi: 10.1037/ccp0000459] [Medline: 31697093]

16. Russell L, Ugalde A, Milne D, Austin D, Livingston PM. Digital characteristics and dissemination indicators to optimize delivery of internet-supported mindfulness-based interventions for people with a chronic condition: systematic review.

JMIR Ment Health 2018 Aug 21;5(3):e53 [FREE Full text] [doi: 10.2196/mental.9645] [Medline: 30131317]

17. Beintner I, Vollert B, Zarski A, Bolinski F, Musiat P, Görlich D, et al. Adherence reporting in randomized controlled trials examining manualized multisession online interventions: systematic review of practices and proposal for reporting standards. J Med Internet Res 2019 Aug 15;21(8):e14181 [FREE Full text] [doi: 10.2196/14181] [Medline: 31414664]

18. Kelders SM, Kok RN, Ossebaard HC, Van Gemert-Pijnen JE. Persuasive system design does matter: a systematic review of adherence to web-based interventions. J Med Internet Res 2012;14(6):e152 [FREE Full text] [doi: 10.2196/jmir.2104] [Medline: 23151820]

19. Ubhi HK, Michie S, Kotz D, van Schayck OC, Selladurai A, West R. Characterising smoking cessation smartphone applications in terms of behaviour change techniques, engagement and ease-of-use features. Transl Behav Med 2016 Sep 23;6(3):410-417 [FREE Full text] [doi: 10.1007/s13142-015-0352-x] [Medline: 27528530]

20. Arnold C, Villagonzalo K, Meyer D, Farhall J, Foley F, Kyrios M, et al. Predicting engagement with an online psychosocial intervention for psychosis: exploring individual- and intervention-level predictors. Internet Interv 2019 Dec;18:100266 [FREE Full text] [doi: 10.1016/j.invent.2019.100266] [Medline: 31890619]

21. Abraham C, Michie S. A taxonomy of behavior change techniques used in interventions. Health Psychol 2008 May;27(3):379-387. [doi: 10.1037/0278-6133.27.3.379] [Medline: 18624603 ]

22. Bardus M, van Beurden SB, Smith JR, Abraham C. A review and content analysis of engagement, functionality, aesthetics, information quality, and change techniques in the most popular commercial apps for weight management. Int J Behav Nutr Phys Act 2016;13(1):35 [FREE Full text] [doi: 10.1186/s12966-016-0359-9] [Medline: 26964880]

23. Banerjee M, Cavanagh K, Strauss C. Barriers to mindfulness: a path analytic model exploring the role of rumination and worry in predicting psychological and physical engagement in an online mindfulness-based intervention. Mindfulness (N Y) 2018 Nov 6;9(3):980-992 [FREE Full text] [doi: 10.1007/s12671-017-0837-4] [Medline: 29875884]

24. Moberg C, Niles A, Beermann D. Guided self-help works: randomized waitlist controlled trial of Pacifica, a mobile app integrating cognitive behavioral therapy and mindfulness for stress, anxiety, and depression. J Med Internet Res 2019 Jun 08;21(6):e12556 [FREE Full text] [doi: 10.2196/12556] [Medline: 31199319]

25. Chien I, Enrique A, Palacios J, Regan T, Keegan D, Carter D, et al. A machine learning approach to understanding patterns of engagement with internet-delivered mental health interventions. JAMA Netw Open 2020 Jul 01;3(7):e2010791 [FREE Full text] [doi: 10.1001/jamanetworkopen.2020.10791] [Medline: $\underline{32678450}$ ]

26. Moher D, Liberati A, Tetzlaff J, Altman DG, PRISMA Group. Preferred reporting items for systematic reviews and meta-analyses: the PRISMA statement. J Clin Epidemiol 2009 Oct;62(10):1006-1012. [doi: 10.1016/j.jclinepi.2009.06.005] [Medline: $\underline{19631508]}$

27. Schardt C, Adams MB, Owens T, Keitz S, Fontelo P. Utilization of the PICO framework to improve searching PubMed for clinical questions. BMC Med Inform Decis Mak 2007 Jun 15;7(1):16 [FREE Full text] [doi: 10.1186/1472-6947-7-16] [Medline: 17573961]

28. Covidence. Veritas Health Innovation Ltd, Australia. URL: https://www.covidence.org/ [accessed 2020-07-08]

29. Huberty J, Green J, Glissmann C, Larkey L, Puzia M, Lee C. Efficacy of the mindfulness meditation mobile app "Calm" to reduce stress among college students: randomized controlled trial. JMIR Mhealth Uhealth 2019 Jun 25;7(6): e14273 [FREE Full text] [doi: 10.2196/14273] [Medline: $\underline{\text { 31237569] }}$

30. Kubo A, Kurtovich E, McGinnis M, Aghaee S, Altschuler A, Quesenberry C, et al. A randomized controlled trial of mHealth mindfulness intervention for cancer patients and informal cancer caregivers: a feasibility study within an integrated health care delivery system. Integr Cancer Ther 2019;18:1534735419850634 [FREE Full text] [doi: 10.1177/1534735419850634] [Medline: 31092044$]$

31. Lindsay EK, Young S, Smyth JM, Brown KW, Creswell JD. Acceptance lowers stress reactivity: dismantling mindfulness training in a randomized controlled trial. Psychoneuroendocrinology 2018 Jan;87:63-73. [doi: 10.1016/j.psyneuen.2017.09.015] [Medline: 29040891]

32. Rosen KD, Paniagua SM, Kazanis W, Jones S, Potter JS. Quality of life among women diagnosed with breast Cancer: a randomized waitlist controlled trial of commercially available mobile app-delivered mindfulness training. Psychooncology 2018 Aug 01;27(8):2023-2030. [doi: 10.1002/pon.4764] [Medline: 29766596] 
33. Thompson NJ, Patel AH, Selwa LM, Stoll SC, Begley CE, Johnson EK, et al. Expanding the efficacy of Project UPLIFT: distance delivery of mindfulness-based depression prevention to people with epilepsy. J Consult Clin Psychol 2015 Apr;83(2):304-313 [FREE Full text] [doi: 10.1037/a0038404] [Medline: 25495361]

34. Wahbeh H. Internet Mindfulness Meditation Intervention (IMMI) improves depression symptoms in older adults. Medicines (Basel) 2018 Nov 02;5(4):119 [FREE Full text] [doi: 10.3390/medicines5040119] [Medline: 30400211]

35. Wahbeh H, Goodrich E, Oken B. Internet-based mindfulness meditation for cognition and mood in older adults: a pilot study. Altern Ther Health Med 2016;22(2):44-53 [FREE Full text] [Medline: 27036056]

36. Bostock S, Crosswell AD, Prather AA, Steptoe A. Mindfulness on-the-go: effects of a mindfulness meditation app on work stress and well-being. J Occup Health Psychol 2019 Feb;24(1):127-138 [FREE Full text] [doi: 10.1037/ocp0000118] [Medline: 29723001]

37. Compen F, Bisseling E, Schellekens M, Donders R, Carlson L, van der Lee M, et al. Face-to-face and internet-based mindfulness-based cognitive therapy compared with treatment as usual in reducing psychological distress in patients with cancer: a multicenter randomized controlled trial. J Clin Oncol 2018 Aug 10;36(23):2413-2421. [doi: $10.1200 /$ jco.2017.76.5669]

38. Kladnitski N, Smith J, Uppal S, James MA, Allen AR, Andrews G, et al. Transdiagnostic internet-delivered CBT and mindfulness-based treatment for depression and anxiety: a randomised controlled trial. Internet Interv 2020 Apr;20:100310 [FREE Full text] [doi: 10.1016/j.invent.2020.100310] [Medline: 32140427]

39. Hearn JH, Finlay KA. Internet-delivered mindfulness for people with depression and chronic pain following spinal cord injury: a randomized, controlled feasibility trial. Spinal Cord 2018 Aug;56(8):750-761. [doi: 10.1038/s41393-018-0090-2] [Medline: 29581519]

40. Henriksson J, Wasara E, Rönnlund M. Effects of eight-week-web-based mindfulness training on pain intensity, pain acceptance, and life satisfaction in individuals with chronic pain. Psychol Rep 2016 Dec;119(3):586-607. [doi: 10.1177/0033294116675086] [Medline: 27780873]

41. Younge JO, Wery MF, Gotink RA, Utens EM, Michels M, Rizopoulos D, et al. Web-based mindfulness intervention in heart disease: a randomized controlled trial. PLoS One 2015;10(12):e0143843 [FREE Full text] [doi: 10.1371/journal.pone.0143843] [Medline: 26641099]

42. Stjernswärd S, Hansson L. Effectiveness and usability of a web-based mindfulness intervention for caregivers of people with mental or somatic illness. A randomized controlled trial. Internet Interv 2018 Jun;12:46-56 [FREE Full text] [doi: 10.1016/j.invent.2018.03.004] [Medline: 30135768]

43. Tavallaei V, Rezapour-Mirsaleh Y, Rezaiemaram P, Saadat SH. Mindfulness for female outpatients with chronic primary headaches: an internet-based bibliotherapy. Eur J Transl Myol 2018 Apr 24;28(2):7380 [FREE Full text] [doi: 10.4081/ejtm.2018.7380] [Medline: 29991985]

44. Donkin L, Christensen H, Naismith SL, Neal B, Hickie IB, Glozier N. A systematic review of the impact of adherence on the effectiveness of e-therapies. J Med Internet Res 2011 Aug;13(3):e52 [FREE Full text] [doi: 10.2196/jmir.1772] [Medline: 21821503]

45. Fish J, Brimson J, Lynch S. Mindfulness interventions delivered by technology without facilitator involvement: what research exists and what are the clinical outcomes? Mindfulness (N Y) 2016 Jun;7(5):1011-1023 [FREE Full text] [doi: 10.1007/s12671-016-0548-2] [Medline: 27642370]

46. Saddichha S, Al-Desouki M, Lamia A, Linden IA, Krausz M. Online interventions for depression and anxiety - a systematic review. Health Psychol Behav Med 2014 Jan 1;2(1):841-881 [FREE Full text] [doi: 10.1080/21642850.2014.945934] [Medline: 25750823]

47. Alsubaie M, Abbott R, Dunn B, Dickens C, Keil TF, Henley W, et al. Mechanisms of action in mindfulness-based cognitive therapy (MBCT) and mindfulness-based stress reduction (MBSR) in people with physical and/or psychological conditions: a systematic review. Clin Psychol Rev 2017 Jul;55:74-91. [doi: 10.1016/j.cpr.2017.04.008] [Medline: 28501707]

48. Riva S, Camerini A, Allam A, Schulz PJ. Interactive sections of an internet-based intervention increase empowerment of chronic back pain patients: randomized controlled trial. J Med Internet Res 2014;16(8):e180 [FREE Full text] [doi: 10.2196/jmir.3474] [Medline: 25119374]

49. Parks AC, Williams AL, Kackloudis GM, Stafford JL, Boucher EM, Honomichl RD. The effects of a digital well-being intervention on patients with chronic conditions: observational study. J Med Internet Res 2020 Jan 10;22(1):e16211 [FREE Full text] [doi: 10.2196/16211] [Medline: $\underline{31922491]}$

\section{Abbreviations}

RCT: randomized controlled trial 
Edited by R Kukafka; submitted 29.04.21; peer-reviewed by H Wahbeh, H Haskelberg; comments to author 18.06.21; revised version received 09.08.21; accepted 12.09.21; published 12.01.22

Please cite as:

Winter N, Russell L, Ugalde A, White V, Livingston P

Engagement Strategies to Improve Adherence and Retention in Web-Based Mindfulness Programs: Systematic Review

$J$ Med Internet Res 2022;24(1):e30026

URL: https://www.jmir.org/2022/1/e30026

doi: $10.2196 / 30026$

PMID:

CNatalie Winter, Lahiru Russell, Anna Ugalde, Victoria White, Patricia Livingston. Originally published in the Journal of Medical Internet Research (https://www.jmir.org), 12.01.2022. This is an open-access article distributed under the terms of the Creative Commons Attribution License (https://creativecommons.org/licenses/by/4.0/), which permits unrestricted use, distribution, and reproduction in any medium, provided the original work, first published in the Journal of Medical Internet Research, is properly cited. The complete bibliographic information, a link to the original publication on https://www.jmir.org/, as well as this copyright and license information must be included. 